\title{
Long-Term Seismic Quiescences and Great Earthquakes in and Around the Japan Subduction Zone Between 1975 and 2012
}

\author{
Kei Katsumata $^{1}$
}

\begin{abstract}
An earthquake catalog created by the International Seismological Center (ISC) was analyzed, including 3898 earthquakes located in and around Japan between January 1964 and June 2012 shallower than $60 \mathrm{~km}$ with the body wave magnitude of 5.0 or larger. Clustered events such as earthquake swarms and aftershocks were removed from the ISC catalog by using a stochastic declustering method based on Epidemic-Type Aftershock Sequence (ETAS) model. A detailed analysis of the earthquake catalog using a simple scanning technique (ZMAP) shows that the long-term seismic quiescences lasting more than 9 years were recognized ten times along the subduction zone in and around Japan. The three seismic quiescences among them were followed by three great earthquakes: the 1994 Hokkaido-toho-oki earthquake $\left(M_{\mathrm{w}} 8.3\right)$, the 2003 Tokachi-oki earthquake $\left(M_{\mathrm{w}} 8.3\right)$, and the 2011 Tohoku earthquake $\left(M_{\mathrm{w}}\right.$ 9.0). The remaining seven seismic quiescences were followed by no earthquake with the seismic moment $M_{0} \geq 3.0 \times 10^{21} \mathrm{Nm}\left(M_{\mathrm{w}} 8.25\right)$, which are candidates of the false alarm. The 2006 Kurile Islands earthquake $\left(M_{\mathrm{w}} 8.3\right)$ was not preceded by the significant seismic quiescence, which is a case of the surprise occurrence. As a result, when limited to earthquakes with the seismic moment of $M_{0} \geq 3.0 \times 10^{21} \mathrm{Nm}$, four earthquakes occurred between 1976 and 2012 in and around Japan, and three of them were preceded by the long-term seismic quiescence lasting more than 9 years.
\end{abstract}

Key words: Seismic quiescence, ZMAP, Seismicity, Earthquake prediction.

\section{Introduction}

No one knows whether a precursory seismicity exists several years or dozen of years before great earthquakes. According to the seismic quiescence hypothesis, the occurrence rate of small earthquakes starts to decrease several years or dozen of years before a great earthquake in and around the focal area

1 Institute of Seismology and Volcanology, Hokkaido University, North-10 West-8, Sapporo 060-0810, Japan. E-mail: kkatsu@mail.sci.hokudai.ac.jp ruptured by a subsequent main shock (Inouye 1965; Utsu 1968; Mogi 1969; Ohtake et al. 1977). Along the Kurile, the Japan and the Ryukyu Trenches, which are one of the active subduction zones in the world, great earthquakes have occurred repeatedly. In this region, four earthquakes shallower than $60 \mathrm{~km}$ are listed on the Global CMT catalog (Dziewonski et al. 1981; Ekström et al. 2012) with the seismic moment larger than $M_{0}=3.0 \times 10^{21} \mathrm{Nm}$ $\left(M_{\mathrm{w}}=8.25\right)$; the 1994 Hokkaido-toho-oki earthquake $\left(M_{0}=3.05 \times 10^{21} \mathrm{Nm}, M_{\mathrm{w}}=8.3\right)$, the 2003 Tokachi-oki earthquake $\left(M_{0}=3.05 \times 10^{21} \mathrm{Nm}\right.$, $\left.M_{\mathrm{w}}=8.3\right)$, the 2006 Kurile Islands earthquake $\left(M_{0}=3.51 \times 10^{21} \mathrm{Nm}, M_{\mathrm{w}}=8.3\right)$, and the 2011 Tohoku earthquake $\left(M_{0}=53.1 \times 10^{21} \mathrm{Nm}\right.$, $\left.M_{\mathrm{w}}=9.1\right)$. Previous studies reported the seismic quiescence prior to these recent great earthquakes. Takanami et al. (1996) pointed out that the seismic quiescence started 3 years before the 1994 Hokkaidotoho-oki earthquake. Katsumata and Kasahara (1999) found that the 1994 event followed the seismic quiescence starting 5-6 years before the main shock. Takahashi and Kasahara (2004) recognized that the seismicity rate decreased in the early 1990s in and around the source volume of the 2003 Tokachi-oki earthquake. Katsumata (2011a) found that the seismic quiescence started 5 years before the 2003 main shock within the Pacific slab subducting beneath the continental plate and suggested that the seismic quiescence was caused by the local stress drop due to a precursory quasi-static pre-slip on the plate boundary. Wyss and Habermann (1979) expressed an intermediate-term earthquake prediction based on the seismic quiescence identified: the location is $45.5^{\circ}-49.2^{\circ} \mathrm{N}$ and $153^{\circ}-155^{\circ} \mathrm{E}$, the length of the seismic fault is from 200 to $400 \mathrm{~km}$, that is, the magnitude is larger 
than 8.0, and the occurrence time is from 1979 to 1994. The predicted location was labeled as L1 and L2 in Fig. 7 of Wyss and Habermann (1979). In this area the 2006 Kurile Islands earthquake occurred on the plate boundary. Consequently the prediction expressed by Wyss and Habermann (1979) was correct in terms of the location and the magnitude; the occurrence time was, however, not correct. Katsumata (2011b) found that a long-term seismic quiescence started 23 years before the 2011 Tohoku earthquake.

Ogata (1992) investigated the seismicity by using the Epidemic Type Aftershock-Sequences (ETAS) model and found that all great earthquakes $(M \approx 8)$ in and around Japan, which occurred between the 1923 Kanto earthquake and the 1968 Tokachi-oki earthquake, were preceded by the statistically significant seismic quiescences. Moreover, he found no significant seismic quiescence between 1968 and 1990 in and around Japan. This is the only previous study that the seismic quiescences associated with great earthquakes were searched systematically in and around Japan. In the time period after 1990, there is no study on the systematic search of the seismic quiescence in and around Japan. Therefore, the purpose of this study is to investigate systematically how often the long-term seismic quiescence is observed between 1976 and 2012 along the Kurile, the Japan, and the Ryukyu Trenches and how many the seismic quiescence is followed by a subsequent great earthquake. The word of "long-term" means the time period of $\sim 10$ years or longer in this study.

\section{Data}

The study area consists of three areas along trenches: the Kurile, the Japan, and the Ryukyu Trenches (Fig. 1; Table 1). The ISC earthquake catalog (International Seismological Centre 2013) was analyzed between 1 January 1964 and 30 June 2012 for the Kurile Trench area and the Ryukyu Trench area and between 1 January 1964 and 28 February 2011 for the Japan Trench area. Since the Tohoku earthquake $\left(M_{\mathrm{w}} 9.1\right)$ occurred on 11 March 2011 in the Japan Trench area and it was followed by many aftershocks, I did not use

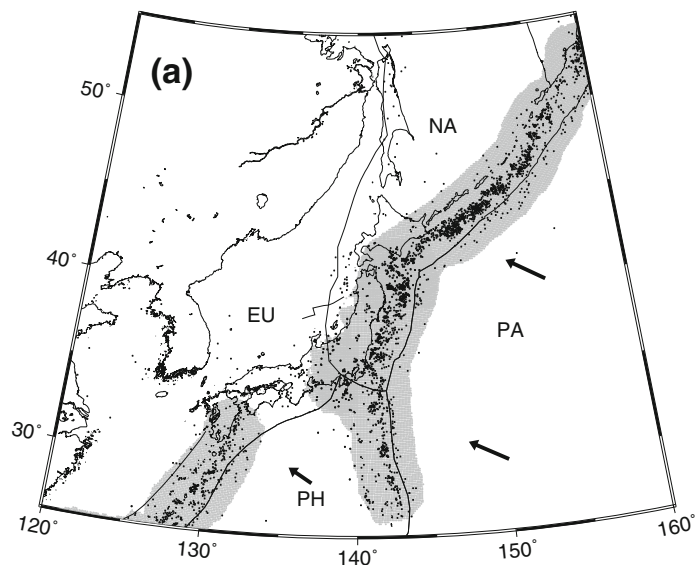

(b)

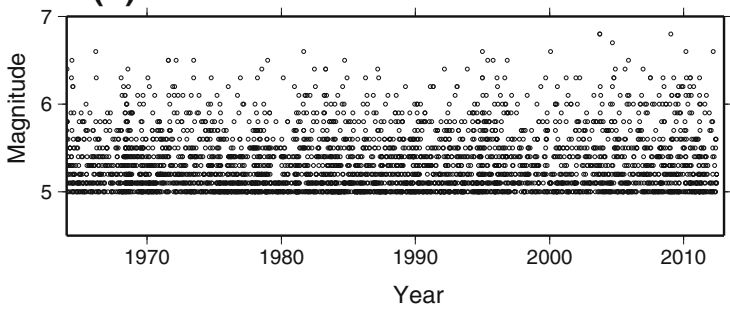

Figure 1

a Map of study area in and around the Japan subduction zone and epicentral distribution of earthquakes used for calculating $Z$ values in this study (1 January 1964-30 June 2012, $m_{\mathrm{b}} \geq 5.0,0 \leq$ depth $(\mathrm{km}) \leq 60)$, which is the ISC earthquake catalog after a declustering process is applied. Hatched areas indicate the nodes with the resolution circle of $r_{\max } \leq 200 \mathrm{~km}$ and the $Z$ values were calculated. Arrows indicate the direction of plate motion relative to the Eurasian plate (DeMets et al. 1994). EU, PA, PH, and NA indicate the Eurasian, the Pacific, the Philippine Sea, and the North American plates, respectively. b A magnitude-time plot for all earthquakes shown in $\mathbf{a}$

earthquakes in the Japan Trench area after the 2011 Tohoku earthquake. When analyzing temporal change in seismicity, it is important to select an adequate kind of the magnitude of earthquake and its range. The surface wave magnitude and the moment magnitude were not used in this study. Since the body wave magnitude $m_{\mathrm{b}}$ has been determined and reported by ISC between 1964 and 2012 continuously, I used the earthquake list with the body wave magnitude $m_{\mathrm{b}}$ in this study. Wiemer and Wyss (2000) developed a method to estimate the magnitude completeness, $M_{\mathrm{c}}$, by plotting the cumulative number of earthquakes versus magnitude. As a result of applying the method to the ISC catalog, $M_{\mathrm{c}}$ is approximately 5.0 for all of the three areas from 1964 to 1970 
Table 1

Parameters for ZMAP in this study

\begin{tabular}{llll}
\hline Trench & Kurile & Japan & Ryukyu \\
\hline Area & $140^{\circ}-160^{\circ} \mathrm{E}, 39^{\circ}-55^{\circ} \mathrm{N}$ & $135^{\circ}-146^{\circ} \mathrm{E}, 26^{\circ}-43^{\circ} \mathrm{N}$ & $120^{\circ}-140^{\circ} \mathrm{E}, 26^{\circ}-40^{\circ} \mathrm{N}$ \\
$T_{\text {start }}$ & 1 January 1964 & 1 January 1964 & 1 January 1964 \\
$T_{\text {end }}$ & 30 June 2012 & 28 February 2011 & 30 June 2012 \\
$m_{\mathrm{b}}$ & $\geq 5.0$ & $\geq 5.0$ & $\geq 5.0$ \\
Depth $(\mathrm{km})$ & $\leq 60.0$ & $\leq 60.0$ & $\leq 60.0$ \\
$N_{\text {eq }}$ & 1641 & 1207 & 1050 \\
Grid size & $0.1^{\circ} \times 0.1^{\circ}$ & $0.1^{\circ} \times 0.1^{\circ}$ & $0.1^{\circ} \times 0.1^{\circ}$ \\
$N_{\text {grid }}$ & 10,510 & 8519 & 8517 \\
$N_{\text {zmap }}$ & 40 & 40 & 40 \\
$r_{\text {max }}(\mathrm{km})$ & $\leq 200$ & $\leq 200$ & $\leq 200$ \\
$\Delta t($ year $)$ & 0.1 & 0.1 & 0.1 \\
$\Delta T($ year $)$ & 9.0 & 9.0 & 9.0 \\
$t_{s}$ (year) & $1975.0 \leq t_{s} \leq 2003.5$ & $1975.0 \leq t_{s} \leq 2002.1$ & $1975.0 \leq t_{s} \leq 2003.5$ \\
$Z$ values & $4,138,970$ & $3,244,596$ & $1,910,112$ \\
$Z \geq+6.0$ & 3771 & 308 & 229 \\
\hline
\end{tabular}

Table 2

List of parameters of the ETAS Model for the ISC catalogue

\begin{tabular}{|c|c|c|c|c|c|c|}
\hline Trench & $A$, events/day & $\alpha, \mathrm{M}^{-1}$ & $c$, day & $p$ & $D^{2}$, degree $^{2}$ & $q$ \\
\hline Kurile & 0.340 & 1.764 & 0.0170 & 1.176 & $6.567 \times 10^{-3}$ & 1.919 \\
\hline Japan & 0.316 & 1.618 & 0.0161 & 1.134 & $6.477 \times 10^{-3}$ & 1.979 \\
\hline Ryukyu & 0.161 & 1.903 & 0.0140 & 1.168 & $4.702 \times 10^{-3}$ & 2.189 \\
\hline
\end{tabular}

and decreases gradually. Thus, I used earthquakes with $m_{\mathrm{b}} \geq 5.0$, which are located without fail between 1964 and 2012, and with a depth of $60 \mathrm{~km}$ and shallower.

A stochastic declustering method developed by Zhuang et al. (2004), which is to remove clustered earthquakes such as swarms and aftershocks, was applied to the ISC catalog. The method of Zhuang et al. (2004) separates seismicity into the background events and the clustered events based on the ETAS model. Since the three study areas extend over a long distance, the declustering process was applied separately for the three areas. Parameters estimated by fitting the ETAS model to the ISC catalog was listed on Table 2. As a result 1641, 1207, and 1050 earthquakes are remained as background events in the Kurile Trench, the Japan Trench, and the Ryukyu Trench areas, respectively, and they are used in the following analysis (Fig. 1).

\section{Method}

A simple space-time scanning technique ZMAP (Wiemer and Wyss 1994) was used to find significant rate changes in seismicity. The ZMAP parameters for the analysis are shown in Table 1 . The study areas are covered by spatial grid points with an interval of $0.1^{\circ} \times 0.1^{\circ}$. The epicentral distance between all pairs of epicenters and the nodes was calculated and $N_{\text {zmap }}=40$ earthquakes were selected around each node in the order that the epicentral distance is short. The spatial resolution $r_{\max }$ for the node is defined by the largest value among the $N_{\text {zmap }}=40$ epicentral distances. The parameter $N_{\text {zmap }}$ is the same value for all nodes in order to compare the statistical significance.

In case of the Kurile Trench and the Ryukyu Trench areas, the $N_{\text {zmap }}=40$ earthquakes took place in a time period between $T_{\text {start }}$ (1 January 1964) and 
$T_{\text {end }}$ (30 June 2012), thus the average rate of occurrence is 40 earthquakes $/ 48.5$ years $=0.82$ earthquakes/year. The $Z$ values are calculated as follows based on the $N_{\text {zmap }}$ earthquakes selected for each node. The time period from $T_{\text {start }}$ and $T_{\text {end }}$ is divided into $N_{\Delta t}$ short-term (ST) time windows at regular intervals with a length of $\Delta t$, which is $\Delta t=0.1$ years and thus $N_{\Delta t}=485$ in case of the Kurile Trench and the Ryukyu Trench areas. The number of earthquakes $n_{i}\left(i=1, \ldots, N_{\Delta t}\right)$ was counted in each ST time window. The background seismicity rate $R_{\mathrm{bg}}$ is then calculated as follows:

$$
R_{\mathrm{bg}}=\frac{1}{n_{\mathrm{bg}}}\left(\sum_{i=1}^{N_{1}} n_{i}+\sum_{i=N_{2}+1}^{N_{\Delta t}} n_{i}\right),
$$

where $n_{\text {bg }}$ is $N_{1}+\left(N_{\Delta t}-N_{2}\right),\left(T_{\text {start }}+N_{1} \Delta t\right) \equiv t_{s}$ is a starting time of a long-term (LT) time window and $\left(T_{\text {start }}+N_{2} \Delta t\right)$ is an ending time of the LT time window. The width of the LT time window $\Delta T=$ $\left(N_{2}-N_{1}\right) \Delta t$ is set to be $\Delta T=9$ years in this study. The seismicity rate $R_{\mathrm{w}}$ was calculated in the LT time window as follows:

$$
R_{\mathrm{w}}=\frac{1}{n_{\mathrm{w}}} \sum_{i=N_{1}+1}^{N_{2}} n_{i},
$$

where $N_{2}-N_{1}$ is equal to $n_{\mathrm{w}}=\Delta T / \Delta t$, which is $n_{\mathrm{w}}=90$ in this study. $R_{\mathrm{w}}$ was compared with $R_{\mathrm{bg}}$ by using the $Z$ value in the following equation:

$$
Z\left(x_{i}, y_{j}, t_{\mathrm{s}}\right)=\left(R_{\mathrm{bg}}-R_{\mathrm{w}}\right)\left(\frac{S_{\mathrm{bg}}}{n_{\mathrm{bg}}}+\frac{S_{\mathrm{w}}}{n_{\mathrm{w}}}\right)^{-\frac{1}{2}},
$$

where $x_{i}\left(i=1, \ldots, n_{\text {lon }}\right)$ and $y_{j}\left(j=1, \ldots, n_{\text {lat }}\right)$ are longitude and latitude of a node, respectively. $t_{s}$ is the starting time of the LT time window and $T_{\text {start }} \leq t_{s} \leq\left(T_{\text {end }}-\Delta T\right) . S_{\text {bg }}$ and $S_{\mathrm{w}}$ are the variances defined by the following equations:

$$
\begin{gathered}
S_{\mathrm{bg}}=\frac{1}{n_{\mathrm{bg}}}\left\{\sum_{i=1}^{N_{1}}\left(n_{i}-R_{\mathrm{bg}}\right)^{2}+\sum_{i=N_{2}+1}^{N_{\Delta t}}\left(n_{i}-R_{\mathrm{bg}}\right)^{2}\right\}, \\
S_{\mathrm{w}}=\frac{1}{n_{\mathrm{w}}} \sum_{i=N_{1}+1}^{N_{2}}\left(n_{i}-R_{\mathrm{w}}\right)^{2} .
\end{gathered}
$$

Taking the spatial resolution into account the nodes with $r_{\max } \leq 200 \mathrm{~km}$ are selected and the $Z$ values are calculated. The number of these nodes is
10,510, 8519, and 8517 in the Kurile Trench, the Japan Trench, and the Ryukyu Trench areas, respectively (Fig. 1). Katsumata (2011a) also described the ZMAP method with a concrete example.

\section{Results}

Figure 2 shows the high- $Z$ anomalies equal to $Z=+6.0$ or larger detected in and around the Japan subduction zone. The positive $Z$ value indicates the seismic quiescence that corresponds to the decrease of seismicity rate in the LT time window with a length of 9 years when comparing with the background rate. The $Z$ values were calculated for the node of $r_{\max } \leq 200 \mathrm{~km}$, and then the total number of $Z$ values are 9,293,678 and the number of $Z$ values with $Z \geq+6.0$ are 4308 . These $4308 Z$ values were divided into ten groups of anomaly taking the spatial and temporal distribution into account (Table 3). Each group is characterized by the location of seismic quiescence, the spatial extent of the seismic quiescence area, the start time and the duration time of the seismic quiescence, the value of $Z$, and the probability that the seismic quiescence is observed by chance if earthquakes occur in random.

The probability by chance was calculated as follows. Assumed that earthquakes occur in random as the Poisson's process, $n$ earthquakes take place in the time period $T$, and $h$ earthquakes take place in the time period $S$. The probability $P$ that this seismicity is observed is calculated by using the following equation (Shimazaki 1973):

$$
P=\left(\begin{array}{c}
r+k-1 \\
k
\end{array}\right) p^{r} q^{k}
$$

$$
p=\frac{T}{T+S}, \quad q=\frac{S}{T+S}, \quad r=n+1, \quad k=h .
$$

For example, in the case of Area 2, $n=20$, $T=17.7$ years, $h=1$, and $S=13.2$ years, thus $P=0.00008$, which is the probability that the seismic quiescence is observed by chance when the earthquakes occur in random. The probability is small significantly for all of the ten anomaly groups, and thus the ten seismic quiescence identified in this 

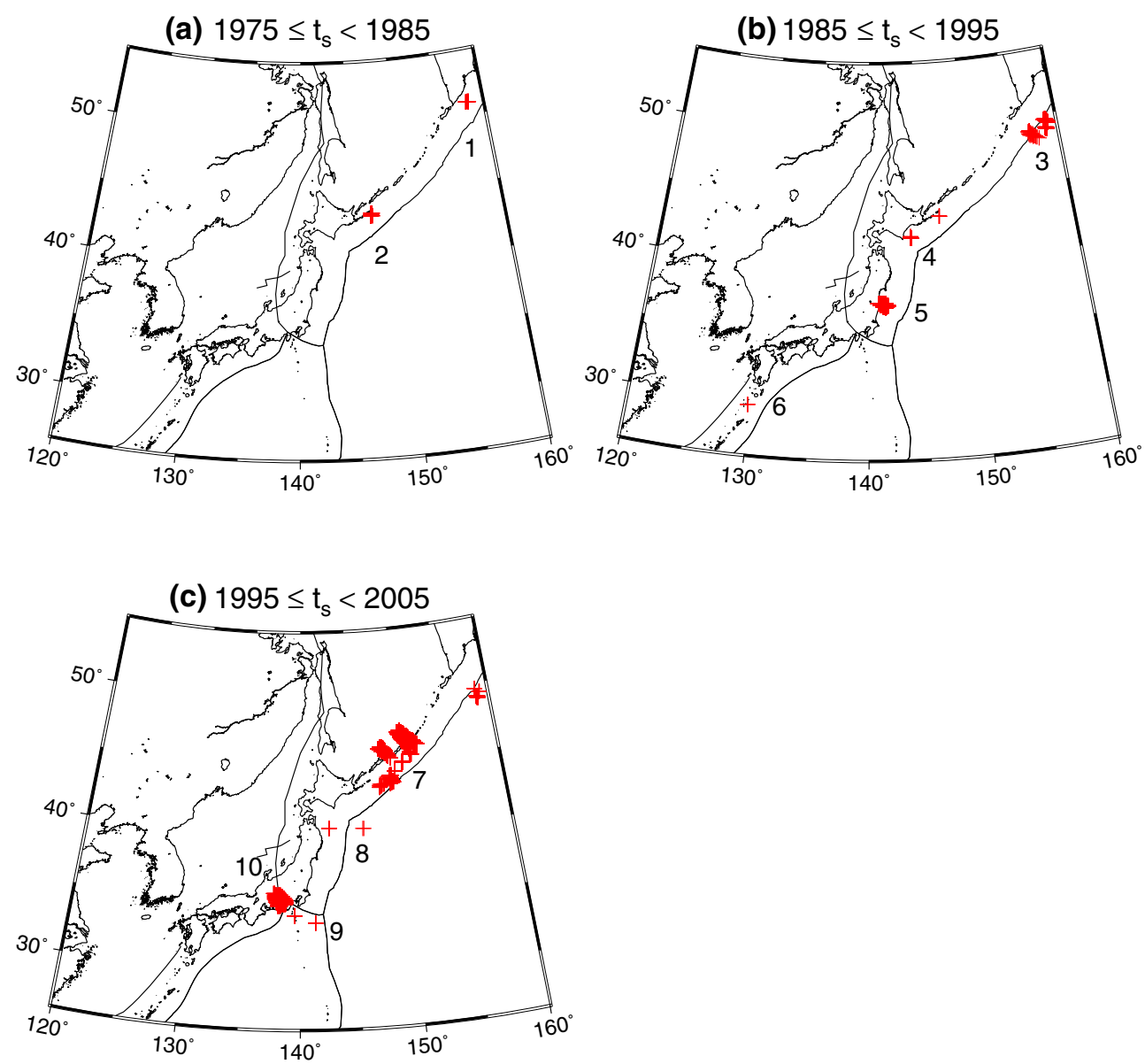

Figure 2

Long-term seismic quiescences found in this study. Red crosses indicate anomalous nodes with the $Z$ value of +6.0 or larger. A positive $Z$ value represents a decrease in the seismicity rate. The long-term time window with a length of $\Delta T=9$ years was used for calculating the $Z$ values. The anomalous nodes are shown in the time period of a $1975 \leq t_{\mathrm{s}}<1985$, b $1985 \leq t_{\mathrm{s}}<1995$, and $\mathbf{c} 1995 \leq t_{\mathrm{s}}<2005$. $t_{\mathrm{s}}$ is the starting time of the long-term time window. The numbers from 1 to 10 indicate the seismic quiescence area shown in Figs. 3, 4, 5, 6, 7 and 8 and Table 3

study are not explained by a random fluctuation in seismicity.

\section{Discussions and Concluding Remarks}

\subsection{Characteristic of Seismic Quiescence}

Figure 3 shows two anomalies in Area 2 and Area 4. In Area 2, the seismic quiescence started in 1981.6, lasting 13.2 years, and ended at the same time as the occurrence of the Hokkaido-toho-oki earthquake $\left(M_{\mathrm{w}}\right.$ 8.3) in 1994, which is not an interplate thrust earthquake but an intraplate earthquake within the PA plate (Kikuchi and Kanamori 1995; Katsumata et al. 1995; Tanioka et al. 1995). The seismic quiescence followed by the 1994 Hokkaido-toho-oki earthquake $\left(M_{\mathrm{w}} 8.3\right)$ has been reported by Takanami et al. (1996) and Katsumata and Kasahara (1999). The duration time of the seismic quiescence is, however, found to be 13.2 years in this study, which is different from the two previous studies. Takanami et al. (1996) pointed out that the seismic quiescence started 3 years before the 1994 main shock. Katsumata and Kasahara (1999) found that the duration time was 5-6 years. Takanami et al. (1996) used earthquakes with $M \geq 3.5$ 
Table 3

Seismic quiescence areas identified in this study

\begin{tabular}{|c|c|c|c|c|c|c|c|}
\hline Area & ${ }^{\circ} \mathrm{N}$ & ${ }^{\circ} \mathrm{E}$ & $r_{\max }(\mathrm{km})$ & Start & $\mathrm{d} t$ (year) & $Z$ & Probability \\
\hline 1 & 51.0 & 158.5 & 159 & 1978.9 & 9.9 & 6.3 & $6 \times 10^{-5}$ \\
\hline 2 & 43.5 & 147.1 & 31 & 1981.6 & 13.2 & 6.4 & $8 \times 10^{-5}$ \\
\hline 3 & 49.6 & 158.8 & 167 & 1993.9 & 10.8 & 6.4 & $2 \times 10^{-5}$ \\
\hline 4 & 42.0 & 144.0 & 51 & 1994.0 & 9.8 & 6.1 & $1 \times 10^{-3}$ \\
\hline 5 & 37.3 & 141.5 & 25 & 1988.0 & 10.6 & 6.6 & $6 \times 10^{-5}$ \\
\hline 6 & 29.6 & 129.9 & 75 & 1985.2 & 9.4 & 6.3 & $6 \times 10^{-5}$ \\
\hline \multirow[t]{2}{*}{7} & 45.9 & 148.6 & 154 & 1996.1 & $\geq 16.4$ & 6.4 & $9 \times 10^{-7}$ \\
\hline & 46.4 & 151.1 & 99 & 1996.9 & 12.4 & 6.4 & $8 \times 10^{-6}$ \\
\hline 8 & 40.5 & 142.7 & 48 & 1996.2 & 12.5 & 6.1 & $6 \times 10^{-4}$ \\
\hline 9 & 33.7 & 141.3 & 46 & 1998.8 & 9.6 & 6.3 & $8 \times 10^{-5}$ \\
\hline 10 & 35.5 & 138.0 & 133 & 1998.3 & 9.4 & 6.4 & $3 \times 10^{-4}$ \\
\hline
\end{tabular}

Area the area numbers are the same as those shown in Fig. 2, $d t$ the duration time of seismic quiescence

between 1 January 1984 and 8 October 1994, which is obviously too short period to recognize the seismic quiescence during 13.2 years. Katsumata and Kasahara (1999) used earthquakes located by Hokkaido University between 1 March 1985 and 3 October 1994 and located by the Japan Meteorological Agency (JMA) between 1 January 1977 and 3 October 1994, which are also too short period to detect the long-term seismic quiescence during 13.2 years found in this study. They also used earthquakes located by ISC between 1 January 1970 and 3 October 1994, which is long enough to detect the 13.2-year-long quiescence. I found a large $Z$ value area near the epicenter of the main shock at the time slices from 1982.5 to 1985.5 in Fig. 8 of Katsumata and Kasahara (1999), which possibly corresponds to the seismic quiescence in this study.

Area 2 is defined by the resolution circle centered at $\left(43.5^{\circ} \mathrm{N}, 147.1^{\circ} \mathrm{E}\right)$ with a radius of $31 \mathrm{~km}$, which is the spatial extent of the seismic quiescence area. Hereafter a term of "the quiescence area" will be used as an abbreviation of "the spatial extent of the seismic quiescence area". In the case of Area 2, the quiescence area includes the epicenter of the main shock. Katsumata et al. (2002) presented a long-term slow slip event (SSE) model preceding to the 1994 main shock based on the tide gauge data. Since the fault plane of the long-term SSE is assumed to be in the quiescence area, the seismic quiescence might be related to the long-term SSE.
In Area 4, the seismic quiescence started in 1994.0, lasting 9.8 years, and ended at the same time of the occurrence of the Tokachi-oki earthquake $\left(M_{\mathrm{w}}\right.$ 8.3) in 2003, which is an interplate earthquake on the interface between the subducting PA plate and the overriding NA plate (Yamanaka and Kikuchi 2003; Yagi 2004; Tanioka et al. 2004; Shinohara et al. 2004). The quiescence area includes the epicenter of the main shock and overlaps with the asperity ruptured by the 2003 event. The seismic quiescence followed by the 2003 Tokachi-oki earthquake $\left(M_{\mathrm{w}}\right.$ 8.3) has been reported by Takahashi and Kasahara (2004) and Katsumata (2011a). The duration time of the seismic quiescence is found to be 9.8 years in this study, which is consistent with Takahashi and Kasahara (2004). Takahashi and Kasahara (2004) analyzed earthquakes with $\mathrm{M} \geq 5.0$ in the JMA catalog from 1952 to 2003 and they obtained the same results as those in this study even if they used the JMA catalog and they did not apply the declustering process. Katsumata (2011a) analyzed earthquakes with $M \geq 3.3$ in a re-determined earthquake catalog between 1994 and 2003 and found that the duration time of the seismic quiescence was 5 years before the 2003 main shock. The earthquake catalog used by Katsumata (2011a) was too short to identify the long-term seismic quiescence during 9.8 years, thus it is not clear whether the results in Katsumata (2011a) are consistent with those in this study. 

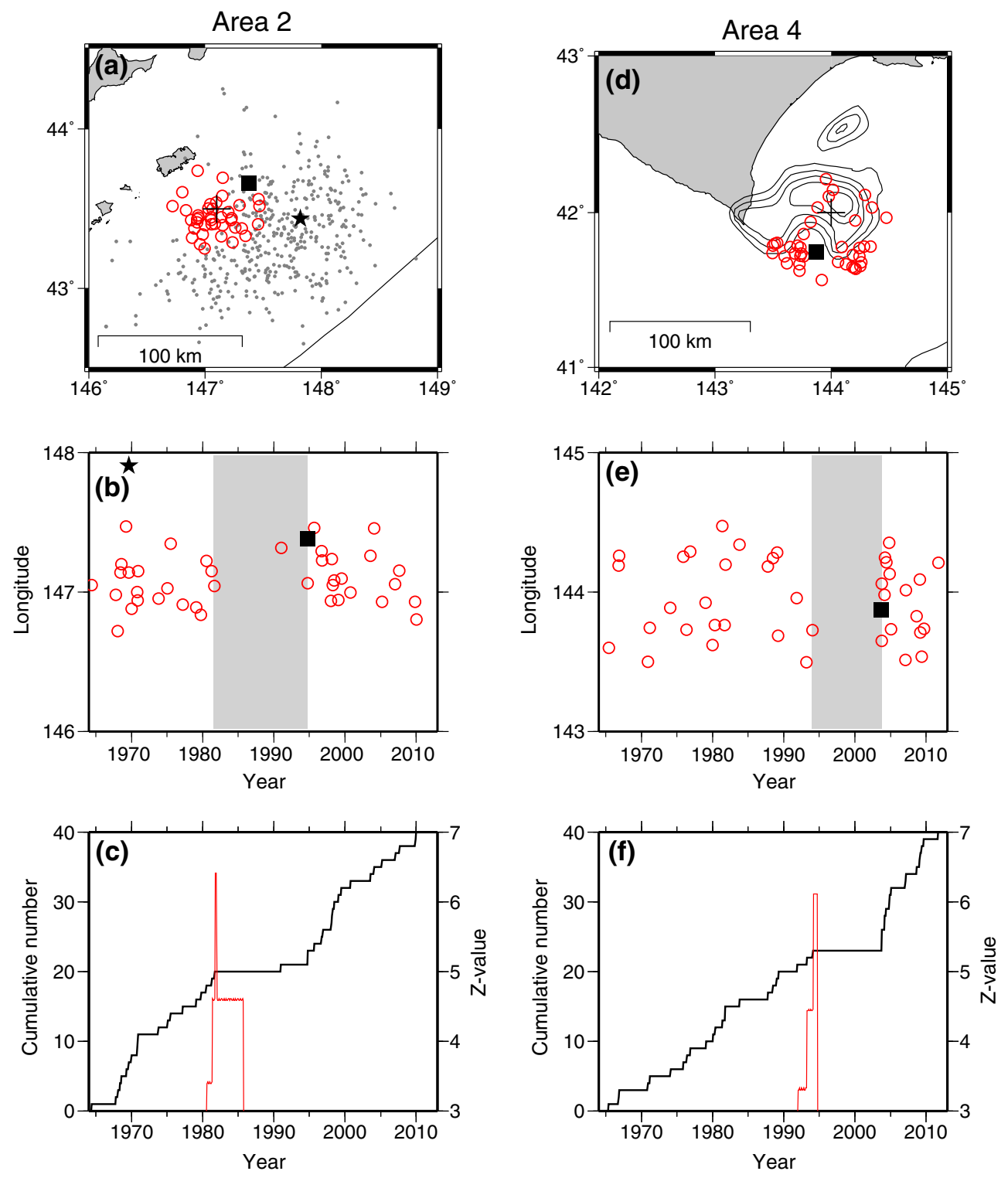

Figure 3

Seismic quiescence in Area $2(\mathbf{a}-\mathbf{c})$ and Area $4(\mathbf{d}-\mathbf{f})$. a Red open circles are $N_{\text {zmap }}=40$ epicenters sampled around the node indicated by a cross. A closed square and a closed star indicate the epicenters of the 1994 and the 1969 Hokkaido-toho-oki earthquakes, respectively, determined by ISC. Gray dots indicate aftershocks of the 1994 event with $M \geq 4.0$ determined by JMA within 1 week after the main shock. The trench axis is shown by a thin line. b Space-time plot of the epicenters shown in $\mathbf{a}$. A gray zone indicates the time period of the long-term seismic quiescence. $\mathbf{c}$ Black lines indicate a cumulative number curve of the epicenters in a and red lines indicate the $Z$ value as a function of time. d Red open circles and a cross indicate the same things as those in a. A closed square is the epicenter of the 2003 Tokachi-oki earthquake determined by ISC. The co-seismic displacement of the fault is shown as contours every $1 \mathrm{~m}$ (Yamanaka and Kikuchi 2003).

e Space-time plot of the epicenters in $\mathbf{d}$. f Cumulative number curve and the $Z$ value plot for the epicenters in $\mathbf{d}$

Figure 4 shows an anomaly in Area 5. The quiescence area is located around the southwestern part of the large slip area of the 2011 Tohoku earthquake $\left(M_{\mathrm{w}}\right.$ 9.0) (e.g., Yokota et al. 2011). In this case the seismic quiescence was observed in a limited area rather than in the whole area of the seismic fault ruptured by the main shock. The seismic quiescence started in 1988.0. No earthquake 


\section{Area 5}
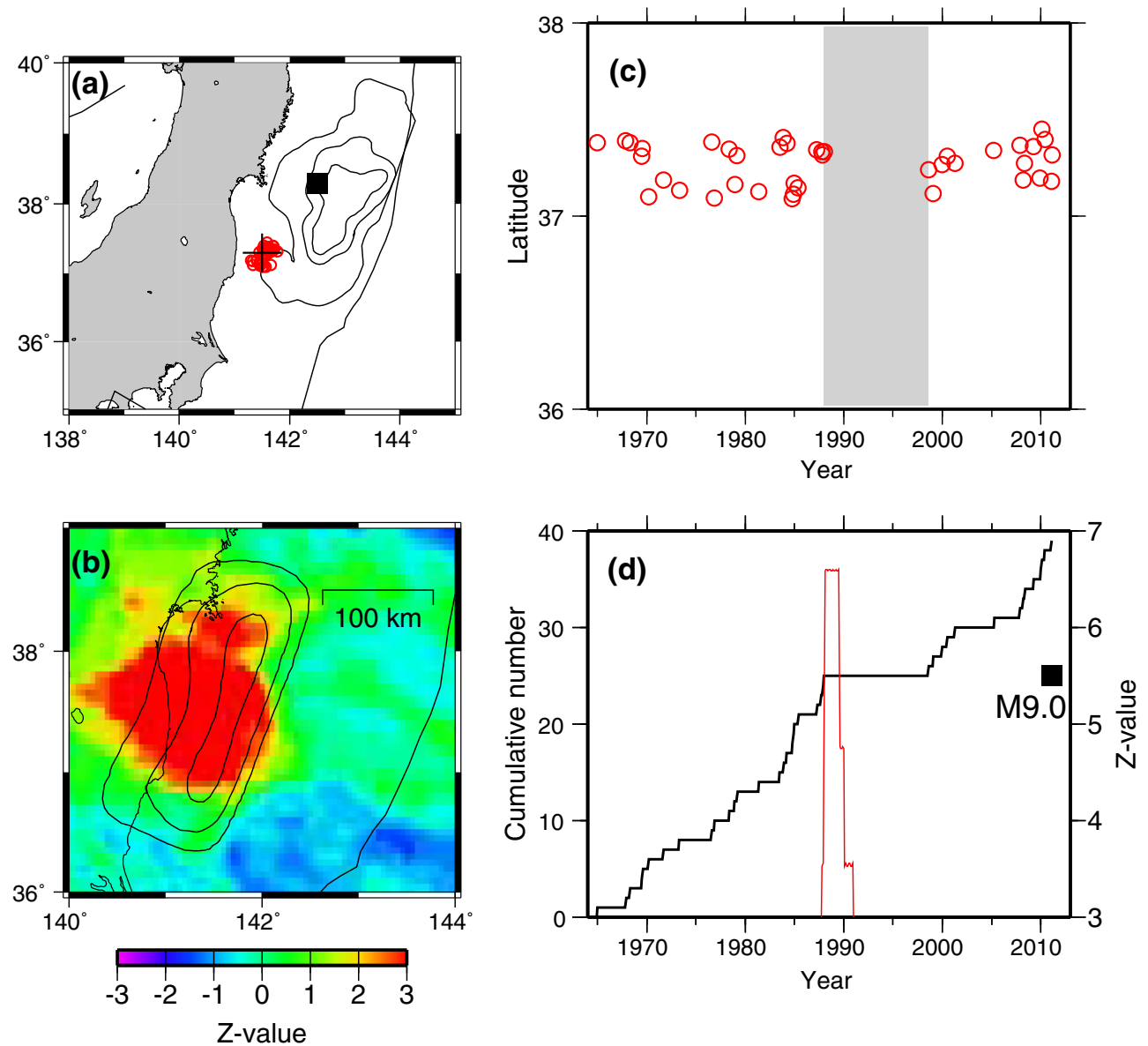

Figure 4

Seismic quiescence in Area 5. a Red open circles are $N_{\text {zmap }}=40$ epicenters sampled around the node indicated by a cross. A closed square indicates the epicenter of the 2011 Tohoku earthquake determined by ISC. The co-seismic displacement of the fault is shown as contours every $10 \mathrm{~m}$ (Yokota et al. 2011). The trench axis is shown by a thin line. b Time slice of $Z$ value distribution and very long-term transient event. The time window starts at $t_{\mathrm{s}}=1988.8$ and ends at $t_{\mathrm{s}}+\Delta T$, where $\Delta T=9$ years. A red color (positive $Z$ value) and blue color (negative $Z$ value) represent a decrease and increase in the seismicity rate, respectively. The displacement of the very long-term transient event is shown as contours every $10 \mathrm{~cm}$ (Yokota and Koketsu 2015). c Space-time plot of the epicenters shown in a. A gray zone indicates the time period of the long-term seismic quiescence. $\mathbf{d}$ Black lines indicate a cumulative number curve of the epicenters in a and red lines indicate the $Z$ value as a function of time

with $m_{\mathrm{b}} \geq 5.0$ occurred from 1988.0 to 1998.6 , the seismicity recovered after 1998.6 with the almost same seismicity rate as that before the seismic quiescence started, and the main shock occurred in 2011.

In the case of the 2011 Tohoku earthquake, the time when the seismic quiescence ended dose not match with the time when the main shock occurred. Therefore, we should examine more carefully whether the seismic quiescence is a long-term precursor to the 2011 main shock or not. First, this seismic quiescence is not a man-made change caused by incomplete earthquake catalog. Katsumata (2011b) analyzed earthquakes with $M \geq 4.5$ in the JMA catalog without the declustering process and found that the seismic quiescence started in 1987.9 in the same area as Area 5 [Fig. 4d in Katsumata (2011b)], which is very consistent with the results in the present study. Second, Yokota and Koketsu (2015) revealed a very long-term transient event 


\section{Area 8}
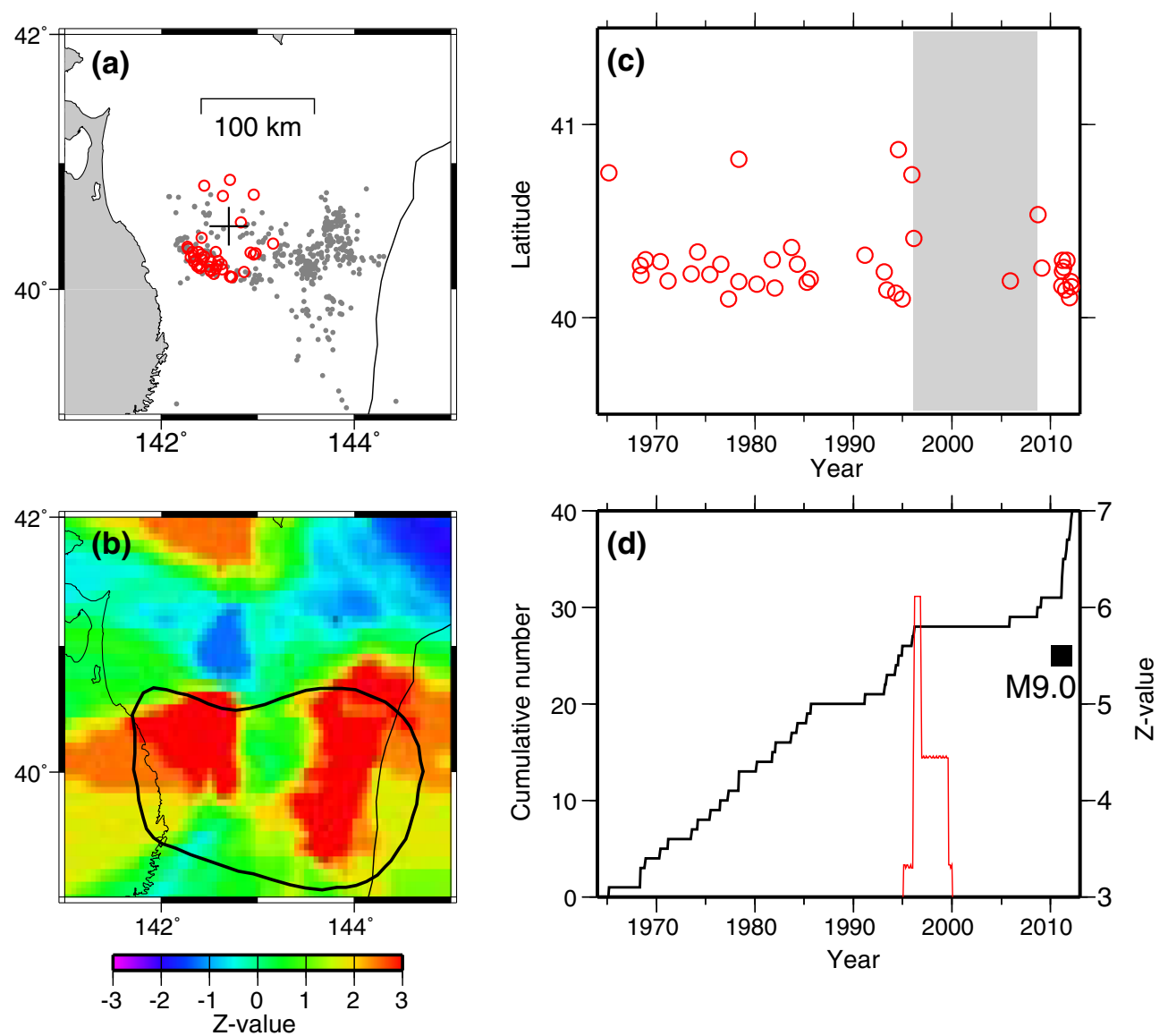

Figure 5

Seismic quiescence in Area 8. a Red open circles are $N_{\mathrm{zmap}}=40$ epicenters sampled around the node indicated by a cross. Gray dots indicate aftershocks of the 1994 Sanriku-oki earthquake with $M \geq 4.0$ determined by JMA within 1 month after the main shock. The trench axis is shown by a thin line. $\mathbf{b}$ Time slice of $Z$ value distribution. The time window starts at $t_{\mathrm{s}}=1996.5$ and ends at $t_{\mathrm{s}}+\Delta T$, where $\Delta T=9$ years. A red color (positive $Z$ value) and blue color (negative $Z$ value) represent a decrease and increase in the seismicity rate, respectively. A thick line shows the area where the interplate coupling recovered (Ozawa et al. 2007). c Space-time plot of the epicenters shown in a. A gray zone indicates the time period of the long-term seismic quiescence. $\mathbf{d}$ Black lines indicate a cumulative number curve of the epicenters in a and red lines indicate the $Z$ value as a function of time

preceding the 2011 Tohoku earthquake $\left(M_{\mathrm{w}} 9.0\right)$, they presented a fault plain model to explain the very long-term transient event. Figure $4 \mathrm{~b}$ is the spatial distribution of $Z$ values at $t_{\mathrm{s}}=1988.8$ and $\mathrm{I}$ found that the quiescence area of Area 5 is located on this fault plain. This spatial matching strongly suggests that the seismic quiescence is related to the very longterm transient event. On the other hand the temporal relationship between the seismic quiescence and the very long-term transient event is not clear. The seismic quiescence started in 1988.0 and a precursory long-term foreshock started in 1998.6. The very longterm transient event started around 2002 (Yokota and Koketsu 2015). Mavrommatis et al. (2014) presented another model that the very long-term transient event started around 1996 and the slip was accelerated toward the main shock in 2011, whereas the fault plain is located at the place similar to that of Yokota and Koketsu (2015). Since there is no GPS data before 1996, it is not clear which time, 1996 or 2002, is plausible as the start time of the very long-term transient event. 
Area 9
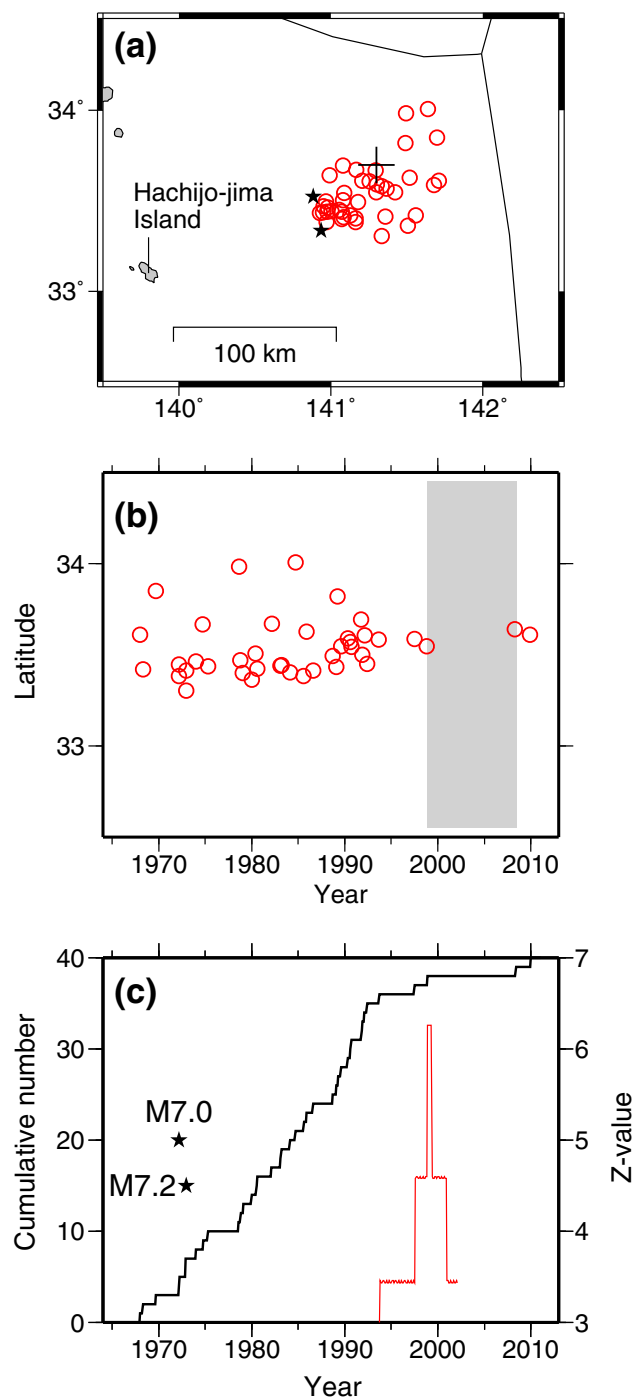

Area 10
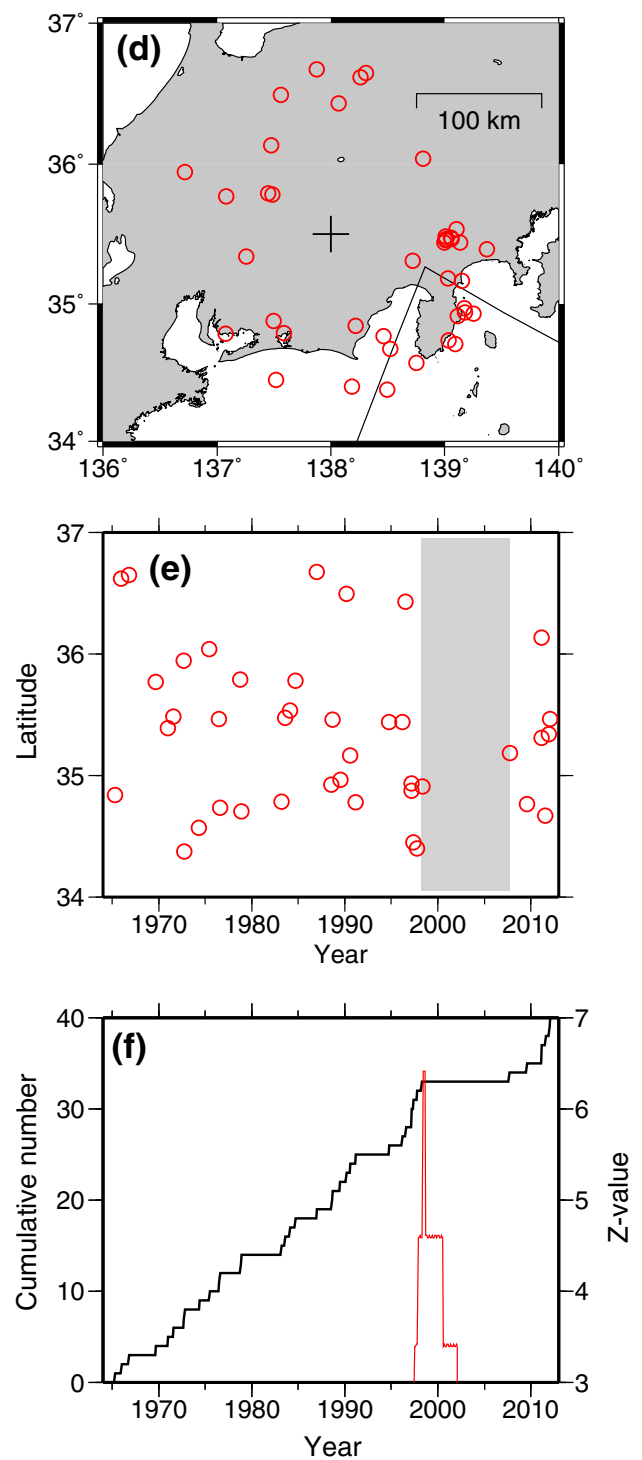

Figure 6

Seismic quiescence in Area $9(\mathbf{a}-\mathbf{c})$ and Area $10(\mathbf{d}-\mathbf{f})$. a Red open circles are $N_{\text {zmap }}=40$ epicenters sampled around the node indicated by a cross. Two closed stars indicate the epicenters of the 1972 Hachijo-jima earthquakes with $M=7.0$ and 7.2 . The trench axis is shown by a thin line. b Space-time plot of the epicenters shown in a. A gray zone indicates the time period of the long-term seismic quiescence. c Black lines indicate a cumulative number curve of the epicenters in a and red lines indicate the $Z$ value as a function of time. $\mathbf{d}$ Red open circles and a cross indicate the same things as those in a. e Space-time plot of the epicenters in $\mathbf{d}$. $\mathbf{f}$ Cumulative number curve and the $Z$ value plot for the epicenters in $\mathbf{d}$

As shown in Fig. 3 the main shocks occurred in the middle of the seismic quiescence in the case of the 1994 Hokkaido-toho-oki earthquake and the 2003 Tokachi-oki earthquake, whereas some M9-class giant earthquakes were preceded by the long-term foreshock activity. Kanamori (1981) reported that the
1964 Alaska earthquake (M9.2) was preceded by the long-term foreshock during about 10 years before the main shock and the 1957 Aleutians earthquake (M9.1) was also preceded by the long-term foreshock during about 8 years before the main shock. Katsumata (2015) reported that the 2004 Sumatra 
Area 7
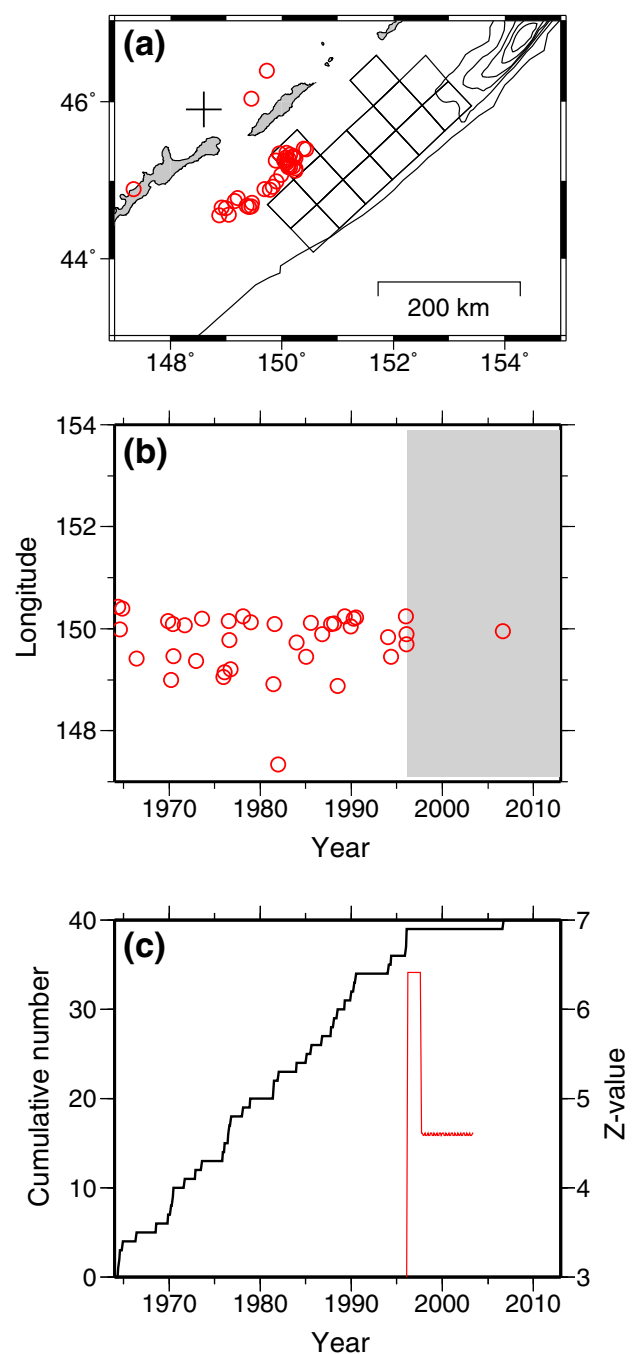

Area 7
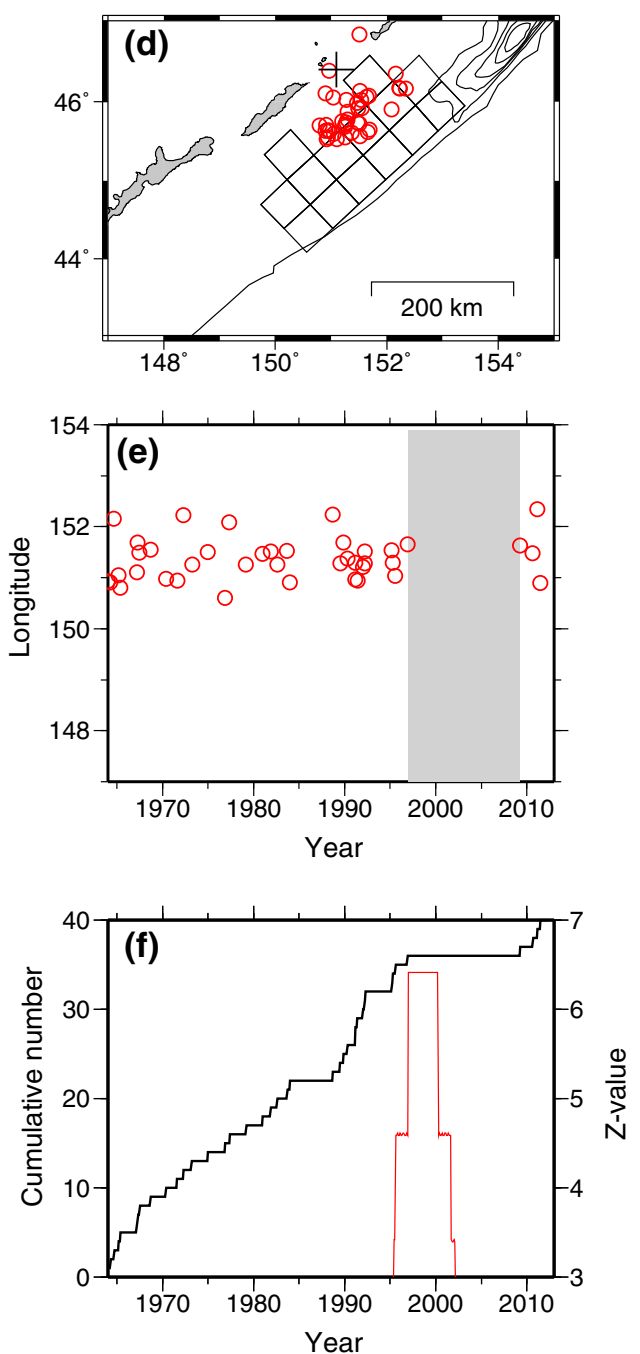

Figure 7

Seismic quiescence in Area 7. a, $\mathbf{d}$ Red open circles are $N_{\mathrm{zmap}}=40$ epicenters sampled around the node indicated by a cross. Fourteen squares are the subfaults of the 1963 Etorof earthquake with the slip of $0.5 \mathrm{~m}$ or larger obtained by Ioki and Tanioka (2011). The co-seismic displacement of the 2006 Kurile earthquake is shown as contours of 1, 3, 5, 7, and $9 \mathrm{~m}$ (Yamanaka 2006). b, e Space-time plot of the epicenters. A gray zone indicates the time period of the long-term seismic quiescence. $\mathbf{c}, \mathbf{d}$ Black lines indicate a cumulative number curve of the epicenters and red lines indicate the $Z$ value as a function of time

earthquake $\left(M_{\mathrm{w}} 9.1\right)$ was preceded by the long-term foreshock during about 5 years before the main shock. Therefore, I suggest that a sequence of the seismic quiescence during about 10 years and the subsequent foreshock activity during about 10 years was an inherent behavior of M9-class earthquakes, and the 2011 Tohoku earthquake was no exception.

Figure 5 shows an anomaly in Area 8. Area 8 includes nine nodes with $Z \geq+6.0$ and one of them is shown in Fig. 5a and Table 3 as a typical anomalous node. The seismic quiescence began in around 1996 after the occurrence of the Sanriku-oki earthquake $\left(M_{\mathrm{w}} 7.7\right)$ on 28 December 1994, which is an interplate thrust earthquake on the upper boundary of the PA plate (Sato et al. 1996; Tanioka et al. 1996; Nakayama and Takeo 1997; Nagai and Kikuchi 2001). Figure $5 b$ is the spatial distribution of $Z$ values at $t_{\mathrm{s}}=1996.5$. The seismicity decreased within the 
Area 1

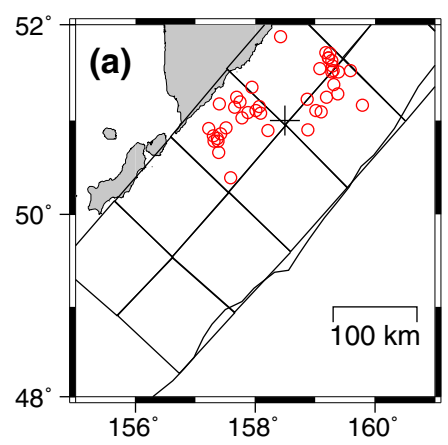

Area 3
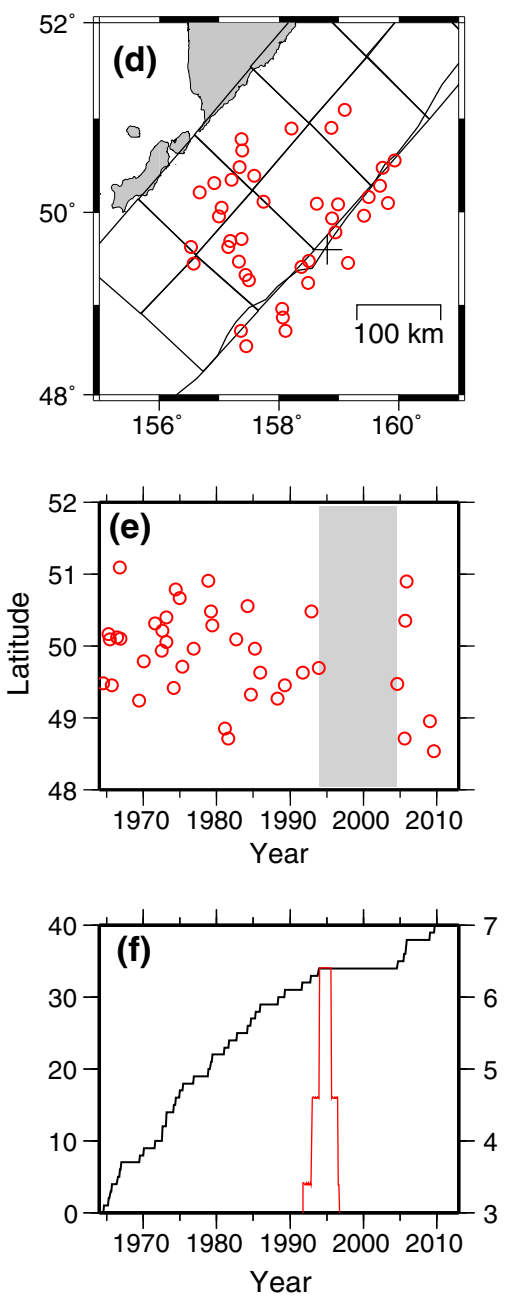

Area 6

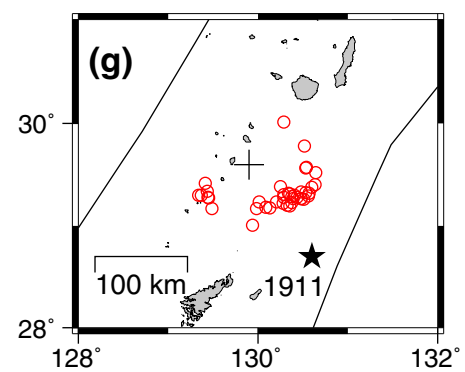

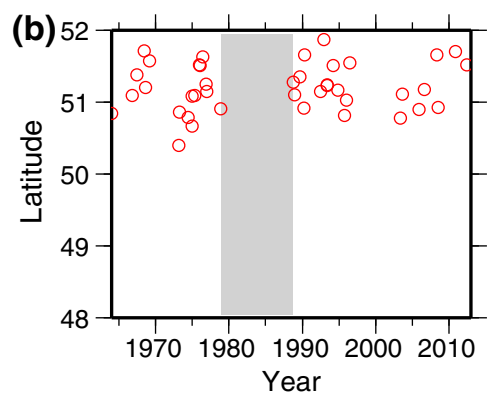

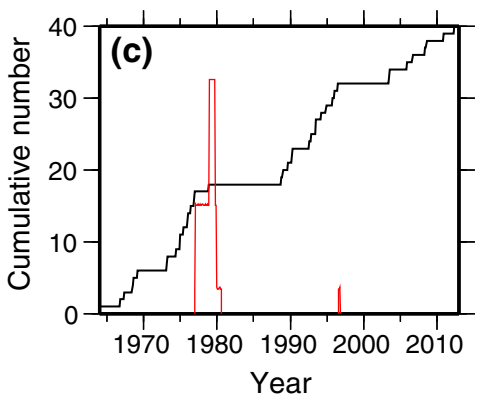

Figure 8

Seismic quiescence in Area $1(\mathbf{a}-\mathbf{c})$, Area $3(\mathbf{d}-\mathbf{f})$ and Area $6(\mathbf{g}-\mathbf{i})$. $\mathbf{a}, \mathbf{d}, \mathbf{g}$ Red open circles are $N_{\mathrm{zmap}}=40$ epicenters sampled around the node indicated by a cross. Squares in a and $\mathbf{d}$ are the subfaults of the 1952 Kamchatka earthquake (M9.0) (Johnson and Satake 1999). The trench axis is shown by a thin line. A closed star in $\mathbf{g}$ is the epicenter of the 1911 great earthquake with $M \sim 8$ (Goto 2013). b, e, h Spacetime plot of the epicenters. A gray zone indicates the time period of the long-term seismic quiescence. c, $\mathbf{f}, \mathbf{i}$ Black lines indicate a cumulative number curve of the epicenters and red lines indicate the $Z$ value as a function of time

area where the interplate coupling recovered (Ozawa et al. 2007). Moreover, the timing of the recovery is well matched with that of starting of the seismic quiescence. These facts suggest that the occurrence of M5-class interplate earthquakes have been suppressed by the strong interplate coupling, which is the reason why the seismic quiescence is observed in Area 8.

Figure 6 shows anomalies in Area 9 and Area 10. In Area 9, the seismic quiescence started in 1998.8, ended in 2008.4, no great earthquake occurred in this area, and thus this seismic quiescence is probably a false alarm. The two earthquakes (M7.0 and M7.2) occurred in 1972 off east coast of Hachijo-jima Island at a depth of around $50 \mathrm{~km}$ and both of the two main shocks were interplate events with a fault plane on the upper surface of the PA plate (Moriyama et al. 1989). This observation indicates that the plate coupling is strong enough to generate a large earthquake even at a depth of $50 \mathrm{~km}$. The two 1972 
events were located around the western boundary of the quiescence area found in this study. Katsumata (2011b) analyzed earthquakes with $M \geq 4.5$ in the JMA catalog without the declustering process and found that the seismic quiescence started in 1992 off east coast of Hachijo-jima Island, which is consistent with the result in this study. In Area 10, the seismic quiescence started in 1998.3, ended in 2007.7, no great earthquake occurred in this area, and thus this seismic quiescence is probably a false alarm. The seismicity decreased clearly within the quiescence area, especially in the south of $35.5^{\circ} \mathrm{N}$. In this area a long-term SSE was observed in this period, which is referred to as the Tokai SSE (Ozawa et al. 2002; Miyazaki et al. 2006; Suito and Ozawa 2009; Ochi and Kato 2013). However the spatial resolution of Area 10 is too poor to reveal that the quiescence area corresponds to the area of the Tokai SSE. Therefore, it is not clear whether the seismic quiescence was related to the Tokai SSE.

Figure 7 shows an anomaly in Area 7. The seismic quiescence started in around 1996 or 1997. Ioki and Tanioka (2011) obtained the slip distribution of the 1963 Etorof earthquake (M8.2) by using the tsunami data. The quiescence area is well matched with the subfaults with the slip of $0.5 \mathrm{~m}$ or larger obtained by Ioki and Tanioka (2011). It is not clear whether this seismic quiescence ended or not.

Figure 8 shows anomalies in Areas 1, 3 and 6. In Area 1, the seismic quiescence started in 1978.9, lasting 9.9 years, ended in 1988.8, and this seismic quiescence was not followed by a great earthquake. The seismic quiescence area is located in the central part of the focal area ruptured by the 1952 Kamchatka earthquake (M9.0) (Johnson and Satake 1999). In Area 3, the seismic quiescence started in 1993.9, lasted 10.8 years, ended in 2004.7, and this seismic quiescence was not followed by a great earthquake, neither. The quiescence area is located in the southwestern part of the 1952 event. These two false alarms on the seismic fault ruptured by the 1952 event possibly suggest that the seismic quiescence occurs frequently in the interseismic period and they are not a precursor to a great earthquake. In Area 6, the seismic quiescence started in 1985.2, lasted 9.4 years, and ended in 1994.6. No large earthquake with $M \geq 7.0$ has been observed in this area from
1964 to 2012 and thus this seismic quiescence should be a false alarm. The seismicity rates are 1.3 events/ year for the period between 1964.0 and 1985.2 and 0.79 events/year for the period between 1994.6 and 2012.5, that is, the seismicity rate has not recovered to the same rate as that before the seismic quiescence. Goto (2013) re-determined the hypocenter of the 1911 great earthquake with $M \sim 8$ and suggested the location of its asperity. The quiescence area in Area 6 is well matched with the northern part of the asperity ruptured by the 1911 event.

\subsection{Seismic quiescences and great earthquakes}

The ten seismic quiescences were identified from 1975 to 2012 in this study. In the same period four great earthquakes occurred with the seismic moment $M_{0} \geq 3.0 \times 10^{21} \mathrm{Nm}\left(M_{\mathrm{w}} \geq 8.25\right)$. The three of ten seismic quiescences were followed by three great earthquakes: the 1994 Hokkaido-toho-oki earthquake $\left(M_{\mathrm{w}} 8.3\right)$, the 2003 Tokachi-oki earthquake $\left(M_{\mathrm{w}} 8.3\right)$, and the 2011 Tohoku earthquake $\left(M_{\mathrm{w}}\right.$ 9.0). The remaining seven seismic quiescences were followed by no earthquake with the seismic moment $M_{0} \geq 3.0 \times 10^{21} \mathrm{Nm}\left(M_{\mathrm{w}} \geq 8.25\right)$, which are candidates of the false alarm. The 2006 Kurile Islands earthquake $\left(M_{\mathrm{w}} 8.3\right)$ was an interplate thrust faulting on the upper boundary of the PA plate (Ji 2006; Yagi 2006; Yamanaka 2006). The 2006 event was not preceded by the significant seismic quiescence with $Z \geq 6.0$, which is a case of the surprise occurrence. To count the cases that no earthquake with $M_{0} \geq 3.0 \times 10^{21} \mathrm{Nm}\left(M_{\mathrm{w}} \geq 8.25\right)$ was observed if no quiescence with $Z \geq+6.0$ is observed, the subduction zone is divided into 17 segments in the study area (Fig. 9). All segments have enough size of the area to generate M8-class earthquakes. Suppose that the earthquake catalog is as long as 40 years. If we assume that the seismic quiescence is 10 years long, the following simple three patterns occur: (1) the first 10 years (background rate) - the second 10 years (quiescence)-the third 10 years (background rate) - the last 10 years (background rate) or (2) the first 10 years (background rate) - the second 10 years (background rate) - the third 10 years (quiescence) - the last 10 years (background rate) or (3) the first 10 years (background rate) - the second 


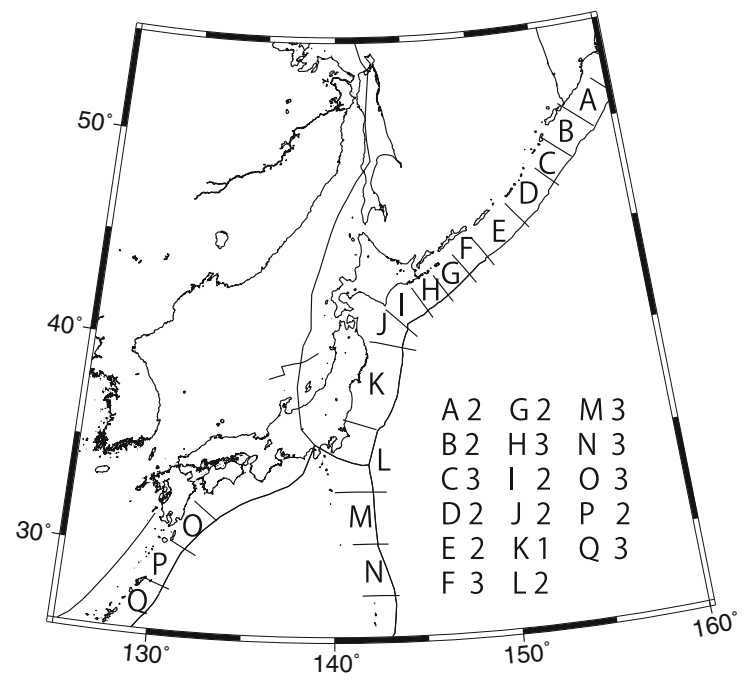

Figure 9

The number of cases that no great earthquake occurs when no longterm seismic quiescence is observed. Seventeen segments are assumed along the subduction zone in and around Japan labeled as $A$ to $Q$

Table 4

2 by 2 table for the seismic quiescence hypothesis

Yes seismic quiescence No seismic quiescence

Yes earthquake $3 \quad 1$

No earthquake $7 \quad 40$

10 years (background rate) - the third 10 years (background rate) - the last 10 years (quiescence). In the present study, the ISC catalog is as long as 48 years from 1964 to 2012 and this is the case of the earthquake catalog 40 years long. Therefore, there are three possible time period of the seismic quiescence in each segment and 17 segments $\times 3$ periods $=51$ periods. Actually, I identified the seismic quiescence 10 times in this study and thus the remaining 41 periods are the case of noearthquake-with-no-seismic-quiescence. In the case of Segment K, which is the focal area of the 2011 Tohoku earthquake, I counted the seismic quiescence two times because of precursory seismicity 20 years long. Consequently the total number of the case of no-quiescence-with-no-earthquake is 40 . A 2 by 2 consistency table was examined by the Fisher's exact test (Table 4). A null hypothesis is that the seismic quiescence has no relation with the occurrence of great earthquake. The probability that the null hypothesis is correct was calculated as follows:

$$
P=\frac{4 ! 47 ! 10 ! 41 !}{51 !} \times\left(\frac{1}{1 ! 3 ! 7 ! 40 !}+\frac{1}{0 ! 4 ! 6 ! 41 !}\right)=0.021,
$$

Therefore the null hypothesis was rejected by $95 \%$ of significant level, that is, the seismic quiescence is related with the occurrence of great earthquake. The probability of 0.021 is, however, not very small; thus, the relationship between the seismic quiescence and the occurrence of great earthquake is weak and further verification is needed in the future work.

\section{Acknowledgments}

I thank two anonymous reviewers for valuable comments. I used a computer code for the spacetime ETAS model and stochastic declustering at http://bemlar.ism.ac.jp/zhuang/software.html. GMTSYSTEM (Wessel and Smith 1991) is used to produce figures. This study was supported by the Ministry of Education, Culture, Sports, Science and Technology (MEXT) of Japan, under its Earthquake and Volcano Hazards Observation and Research Program. This work was supported by JSPS KAKENHI Grant Number 26400445.

Open Access This article is distributed under the terms of the Creative Commons Attribution 4.0 International License (http:// creativecommons.org/licenses/by/4.0/), which permits unrestricted use, distribution, and reproduction in any medium, provided you give appropriate credit to the original author(s) and the source, provide a link to the Creative Commons license, and indicate if changes were made.

\section{REFERENCES}

DeMets, C., Gordon, R. G., Argus, D. F., \& Stein, S. (1994). Effect of recent revisions to the geomagnetic reversal time scale on estimation of current plate motions. Geophysical Research Letters, 21, 2191-2194.

Dziewonski, A. M., Chou, T.-A., \& Woodhouse, J. H. (1981). Determination of earthquake source parameters from waveform data for studies of global and regional seismicity. Journal of Geophysical Research, 86, 2825-2852. 
Ekström, G., Nettles, M., \& Dziewonski, A. M. (2012). The global CMT project 2004-2010: Centroid-moment tensors for 13,017 earthquakes. Physics of the Earth and Planetary Interior, 200-201, 1-9.

Goto, K. (2013). Re-evaluation of hypocenter of the 1911 great earthquake around Kikai-jima, Japan. Journal of the Seismological Society of Japan (Zisin), 65, 231-242. (in Japanese).

Inouye, W. (1965). On the seismicity in the epicentral region and its neighborhood before the Niigata earthquake. Kenshin-jiho (Quarterly Journal of Seismology), 29, 139-144. (in Japanese).

International Seismological Centre (2013). On-line Bulletin. International Seismological Center, Thatcham, United Kingdom. http://www.isc.ac.uk/iscbulletin/search/catalogue/. Accessed 7 Apr 2016.

Ioki, K., \& Tanioka, Y. (2011). Slip distribution of the 1963 great Kurile earthquake estimated from tsunami waveforms. Pure and Applied Geophysics, 168, 1045-1052.

Ji, C. (2006). Rupture process of the 2006 NOV 15 magnitude 8.3KURIL Island earthquake (revised). http://earthquake.usgs.gov/ eqcenter/eqinthenews/2006/usvcam/finite_fault.php. Accessed Mar 2016.

Johnson, J. M., \& Satake, K. (1999). Asperity distribution of the 1952 great Kamchatka earthquake and its relation to future potential in Kamchatka. Pure and Applied Geophysics, 154, 541-553.

Kanamori, H. (1981). The nature of seismicity patterns before large earthquakes. In W. Simpson \& P. G. Richards (Eds.), Earthquake prediction maurice ewing series $4 D$ (pp. 1-19). Washington: American Geophysical Union.

Katsumata, K. (2011a). Precursory seismic quiescence before the $\mathrm{M}_{\mathrm{w}}=8.3$ Tokachi-oki, Japan earthquake on 26 September 2003 revealed by a re-examined earthquake catalog. Journal of Geophysical Research,. doi:10.1029/2010JB007964.

Katsumata, K. (2011b). A long-term seismic quiescence started 23 years before the 2011 off the Pacific coast of Tohoku earthquake $(M=9.0)$. Earth, Planets and Space, 63, 709-712.

Katsumata, K. (2015). A long-term seismic quiescence before the 2004 Sumatra $\left(\mathrm{M}_{\mathrm{w}} 9.1\right)$ earthquake. Bulletin of the Seismological Society of America, 105(1), 167-176.

Katsumata, K., Ichiyanagi, M., Miwa, M., Kasahara, M., \& Miyamachi, H. (1995). Aftershock distribution of the October 4, $1994 \mathrm{M}_{\mathrm{w}} 8.3$ Kurile islands earthquake determined by a local seismic network in Hokkaido. Japan. Geophysical Research Letters, 22, 1321-1324.

Katsumata, K., \& Kasahara, M. (1999). Precursory seismic quiescence before the 1994 Kurile earthquake $\left(M_{w}=8.3\right)$ revealed by three independent seismic catalogs. Pure and Applied Geophysics, 155, 443-470.

Katsumata, K., Kasahara, M., Ozawa, S., \& Ivashchenko, S. (2002). A five years super-slow aseismic precursor model for the 1994 M8.3 Hokkaido-Toho-Oki lithospheric earthquake based on tide gauge data. Geophysical Research Letters, doi:10.1029/2002GL014982.

Kikuchi, M., \& Kanamori, H. (1995). The Shikotan earthquake of October 4, 1994: lithospheric earthquake. Geophysical Research Letters, 22, 1025-1028.

Mavrommatis, A. P., Segall, P., \& Johnson, K. M. (2014). A decadal-scale deformation transient prior to the $2011 \mathrm{M}_{\mathrm{w}} 9.0$ Tohoku-oki earthquake. Geophysical Research Letters, 41, 4486-4494. doi:10.1002/2014GL060139.

Miyazaki, S., Segall, P., McGuire, J. J., Kato, T., \& Hatanaka, Y. (2006). Spatial and temporal evolution of stress and slip rate during the 2000 Tokai slow earthquake. Journal of Geophysical Research, 111, B03409. doi:10.1029/2004JB003426.

Mogi, K. (1969). Some feature of recent seismic activity in and near Japan (2), Activity before and after great earthquakes. Bulletin of Earthquake Research Institute, Tokyo University, 47, 395-417.

Moriyama, T., Tajima, F., \& Seno, T. (1989). The unusual zone of seismic coupling in the Bonin arc: the 1972 Hachijo-Oki earthquakes and related seismicity. Pure and Applied Geophysics, 129, 233-261.

Nagai, R., \& Kikuchi, M. (2001). Comparative study on the source processes of recurrent large earthquake in Sanriku-oki region: the 1968 Tokachi-oki earthquake and the 1994 Sanriku-oki earthquake. Journal of the Seismological Society of Japan (Zisin), 54, 267-280. (in Japanese).

Nakayama, W., \& Takeo, M. (1997). Slip history of the 1994 Sanriku-Haruka-Oki, Japan, earthquake deduced from strongmotion data. Bulletin of Seismological Society of America, 87, 918-931.

Ochi, T., \& Kato, T. (2013). Depth extent of the long-term slow slip event in the Tokai district, central Japan: a new insight. Journal of Geophysical Research, 118, 4847-4860. doi:10.1002/ jgrb.50355.

Ogata, Y. (1992). Detection of precursory relative quiescence before great earthquakes through a statistical model. Journal of Geophysical Research, 97, 19845-19871.

Ohtake, M., Matsumoto, T., \& Latham, G. V. (1977). Seismicity gap near Oaxaca, Southern Mexico as a probable precursor to a large earthquake. Pure and Applied Geophysics, 115, 375-386.

Ozawa, S., Murakami, M., Kaidzu, M., Tada, T., Sagiya, T., Hatanaka, Y., et al. (2002). Detection and monitoring of ongoing aseismic slip in the Tokai region, central Japan. Science, 298, 1009-1012.

Ozawa, S., Suito, H., Nishimura, T., Tobita, M., \& Munekane, H. (2007). Possibility of recovery of slip deficit rate between the North American plate and the Pacific plate off Sanriku, northeast Japan. Geophysical Research Letters, 34, L20308. doi:10.1029/ 2007 GL030477.

Sato, T., Imanishi, K., \& Kosuga, M. (1996). Three-stage rupture process of the 28 December 1994 Sanriku-Oki earthquake. Geophysical Research Letters, 23, 33-36.

Shimazaki, K. (1973). Statistical method of detecting unusual seismic activities. Bulletin of Seismological Society of America, 63, 969-982.

Shinohara, M., et al. (2004). Aftershock observation of the 2003 Tokachi-oki earthquake by using dense ocean bottom seismometer network. Earth, Planets and Space, 56, 295-300.

Suito, H., \& Ozawa, S. (2009). Transient crustal deformation in the Tokai district-The Tokai slow slip event and postseismic deformation caused by the 2004 off southeast Kii Peninsula earthquake (in Japanese). Journal of the Seismological Society of Japan (Zisin), 61, 113-135.

Takahashi, H., \& Kasahara, M. (2004). The 2003 Tokachi-oki earthquake off southeastern Hokkaido, Japan—seismic activity from the former 1952 Tokachi-oki earthquake, foreshock, mainshock, aftershocks, and triggered earthquakes. Journal of Seismological Society of Japan, 57, 115-130. (in Japanese).

Takanami, T., Sacks, I. S., Snoke, J. A., Motoya, Y., \& Ichiyanagi, M. (1996). Seismic quiescence before the Hokkaido-Toho-Oki earthquake of October 4, 1994. Journal of Physics of the Earth, 44, 193-203. 
Tanioka, Y., Hirata, K., Hino, R., \& Kanazawa, T. (2004). Slip distribution of the 2003 Tokachi-oki earthquake estimated from tsunami waveform inversion. Earth, Planets and Space, 56, 373-376.

Tanioka, Y., Ruff, L., \& Satake, K. (1995). The great Kurile earthquake of October 4, 1994 tore the slab. Geophysical Research Letters, 22, 1661-1664.

Tanioka, Y., Ruff, L., \& Satake, K. (1996). The Sanriku-Oki, Japan, earthquake of December 28, $1994\left(\mathrm{M}_{\mathrm{w}} 7.7\right)$ : Rupture of different asperity from a previous earthquake. Geophysical Research Letters, 23, 1465-1468.

Utsu, T. (1968). Seismic activity in Hokkaido and its vicinity. Geophysical Bulletin of Hokkaido University, 13, 99-103. (in Japanese).

Wessel, P., \& Smith, W. H. F. (1991). Free software helps map and display data. Eos Transaction of AGU, 72, 445-446.

Wiemer, S., \& Wyss, M. (1994). Seismic quiescence before the Landers $(M=7.5)$ and Big Bare $(M=6.5) 1992$ earthquakes. Bulletin of Seismological Society of America, 84, 900-916.

Wiemer, S., \& Wyss, M. (2000). Minimum magnitude of completeness in earthquake catalogs: examples from Alaska, the western United States, and Japan. Bulletin of Seismological Society of America, 90, 859-869.

Wyss, M., \& Habermann, R. E. (1979). Seismic quiescence precursory to a past and a future Kurile Island earthquake. Pure and Applied Geophysics, 117, 1195-1211.
Yagi, Y. (2004). Source rupture process of the 2003 Tokachi-oki earthquake determined by joint inversion of teleseismic body wave and strong ground motion data. Earth, Planets and Space, 56, 311-316.

Yagi, Y. (2006). http://www.geo.tsukuba.ac.jp/press_HP/yagi/EQ/ Chishima/. Accessed Mar 2016.

Yamanaka, Y. (2006). http://wwweic.eri.u-tokyo.ac.jp/sanchu/ Seismo_Note/2006/EIC183.html. Accessed Mar 2016.

Yamanaka, Y., \& Kikuchi, M. (2003). Source process of the recurrent Tokachi-oki earthquake on September 26, 2003, inferred from teleseismic body waves. Earth, Planets and Space, 55(12), e21-e24.

Yokota, Y., \& Koketsu, K. (2015). A very long-term transient event preceding the 2011 Tohoku earthquake. Nature Communications, 6, 5934. doi:10.1038/ncomms6934.

Yokota, Y., Koketsu, K., Fujii, Y., Satake, K., Sakai, S., Shinohara, M., et al. (2011). Joint inversion of strong motion, teleseismic, geodetic, and tsunami datasets for the rupture process of the 2011 Tohoku earthquake. Geophysical Research Letters, 38, L00G21. doi:10.1029/2011GL050098.

Zhuang, J., Ogata, Y., \& Vere-Jones, D. (2004). Analyzing earthquake clustering features by using stochastic reconstruction. Journal of Geophysical Research, 109, B05301. doi:10.1029/ 2003JB002879.

(Received April 7, 2016, revised September 7, 2016, accepted October 8, 2016, Published online October 21, 2016) 